\title{
A comparative thermodynamic analysis of air handling units at variable reference temperature
}

Vytautas Martinaitis*,1, Giedre Streckiene $^{1}$, Audrius Bagdanavicius ${ }^{2}$, Juozas Bielskus ${ }^{1}$

${ }^{1}$ Department of Building Energetics, Vilnius Gediminas Technical University, Sauletekio ave. 11, LT-10223 Vilnius, Lithuania

${ }^{2}$ Department of Engineering, University of Leicester, University Road, Leicester LE1 7RH, United Kingdom

*Corresponding author. Tel.: +370 52512297, E-mail address: vytautas.martinaitis@vgtu.lt (V. Martinaitis).

\begin{abstract}
Ventilation and air conditioning systems are emerging as the major energy consumers in low energy buildings. The objective of this paper is to present new methodology for assessment of Air Handling Units (AHUs) taking into account the variations of reference temperature. The methodology using the concept of coenthalpy, developed for heat exchangers and published by the authors previously has been used. Four AHUs that comprise energy transfer devices, such as: Water-to-Air Heater (WAH), Heat Recovery Exchanger (HRE) and Heat Pump (HP) have been investigated. Thermodynamic parameters including Coefficient of Performance (COP), universal and functional exergy efficiencies have been used to compare AHUs and to calculate the exergy destruction in AHU components at variable environment temperature $-30^{\circ} \mathrm{C} \ldots+10^{\circ} \mathrm{C}$. The results of this study show that using HRE the COP and exergy efficiencies are significantly better compared with AHU without HRE. Using the HRE of higher effectiveness, the thermodynamic indicators can be improved considerably. The study shows that AHUs equipped with HP with advanced control method and HRE are more advantageous compared with other investigated AHUs.

The presented methodology could have practical application for evaluating of energy and exergy efficiency of AHUs at different reference temperatures when designing HVAC systems and implementing optimum control methods.
\end{abstract}

Keywords: HVAC systems; exergy analysis; variable reference temperature; universal and functional exergy efficiency; performance of air handling unit; coenthalpy. 


\section{Introduction}

In recent decades, due to stricter energy efficiency requirements the thermal performance of buildings has been rapidly improving. Due to increased thermal insulation of building envelope the heat demand for space heating reduces [1]. Therefore, in modern low energy buildings the major energy consumers are ventilation and air conditioning systems that are designed to provide air of suitable quality [2,3]. To save thermal energy in airtight and well insulated buildings the ventilation systems with heat recovery units are often recommended. Therefore, improvement of those systems is of vital importance in order to achieve better indoor climate and to reduce energy consumption in buildings $[4,5]$.

To investigate Heating Ventilation and Air Conditioning (HVAC) systems, which can consist of different subsystems, a variety of methods can be used. One of those methods is thermodynamic or exergy analysis. Using this method, the quality of energy could be evaluated [6-8]. Exergy is a useful quantity that stems from the combination of the second and first laws of thermodynamics. The exergy of a system is defined as the maximum shaft work that can be done by the system at a specified reference environment $[9,10]$. The thermodynamic reference environment (temperature or pressure) "acts as an infinite system, and is a sink and source for heat and materials" [11]. When exergy analysis is used it is important to follow universal principles of the method that could be applied for system components or whole systems. Therefore, the choice of reference environment, which can be constant, variable or averaged over the chosen period is a very important step. For example, in an important study on low exergy buildings it "is recommended to use the (current) surrounding outdoor air as the reference environment for the exergy analysis of buildings and their energy supply systems" [12]. However, there is no recommendation in this study how to conduct the exergy analysis when the reference temperature is variable.

HVAC systems are the systems where the temperatures of the working fluids are close to the environment temperatures. However, there is no strict agreement among researchers what reference temperature should be used when conducting exergy analysis of those systems. Some researchers recommend using the reference (dead) state temperature, which is based on the daily or monthly average temperature [13] or on the average annual temperature of particular location [14]. Others perform studies based on seasonal temperatures $[3,15,16]$. Torío et al. [17] has conducted research on the selection of the reference temperature for the exergy analysis. Their review study shows that when the properties of a system are close to those of the reference environment, results from the exergy analysis undergo strong variations depending on the definition of the reference environment chosen. 
Therefore, when analysing HVAC systems it is extremely important to choose appropriate reference temperature. It is worth mentioning that, as noticed by Laverge and Janssens, "the use of average temperatures to calculate the Carnot efficiency therefore introduces an error" [18]. This is not always taken into account when conducting exergy analysis of HVAC systems.

The exergy analysis can be used to analyse the whole system or to investigate separate subsystems or system components. One of the objectives of the exergy analysis is to improve the efficiency of energy conversion systems and to identify components where the exergy destruction occurs. Also, an optimisation of energy conversion processes could be performed using the exergy parameters as indicators. The operation of energy conversion systems depends on the efficiency of separate components and subsystems, operating conditions and control strategies [6].

There are many studies on the exergy analysis of HVAC systems and components. The exergy analysis of air conditioning and refrigeration systems were presented by Dincer and Rosen [9], where the effect of the reference temperature on the results of exergy analysis was shown. Review studies on application of exergy analysis were published by Torío et al., Hepbasli, Park et al., [17,19,20]. The exergy analysis of building energy systems using the low exergy principle was presented in $[12,21,22]$. The exergy analysis of heat exchangers for HVAC systems was conducted by Martinaitis and Streckiene [23], and dehumidification and other processes were analysed in [24,25].

Chengqin et al. [26] evaluated four evaporative cooling systems at two ambient temperature conditions $\left(+33^{\circ} \mathrm{C}\right.$ and $\left.+36^{\circ} \mathrm{C}\right)$. Their results showed that the effectiveness of the heat exchanger of the indirect evaporative cooling system was important in improving the exergy efficiency of the regenerative system.

Wei and Zmeureanu [15] presented the exergy analysis of variable air volume systems for airconditioning. Two thermodynamic indicators: Coefficient of Performance (COP) and exergy efficiency were used. Variable environment temperature between $-30^{\circ}$ and $+30^{\circ} \mathrm{C}$ was assumed in this study. The results of the study showed that "the use of electricity as an energy source for heating or cooling in a HVAC system is not a thermodynamically sound choice". Therefore, one way to improve the exergy efficiency of the system is to change the heating source from electricity to renewable energy sources such as: waste heat, geothermal or solar. Besides, the authors conclude that the energy analysis should be combined with the exergy analysis when assessing the performance of buildings and HVAC systems.

Comparison of buoyancy-driven ventilation system with mechanical ventilation system was presented by Wang and Li [27]. The results of their study showed that the exergy efficiency of the 
buoyancy-driven ventilation system is very poor and the exergy destruction accounts for $83.1 \%$ of the total exergy input. Although the authors conducted analysis at constant environment temperature, they concluded that in future the investigation of exergy efficiencies of ventilation systems dynamically taking "the whole energy consuming chain into account" should be conducted.

Cumulative exergy analysis method to analyse different air conditioning systems was used by $\mathrm{Pu}$ et al. [28]. Although the calculations were conducted at constant environment temperature of $35.1^{\circ} \mathrm{C}$ the authors observed that cumulative exergy values are sensitive to the reference temperature. It was reported that the exergy efficiency and the cumulative exergy efficiency increase when the dead state (reference) temperature increases. Moreover, the authors conclude that "the effect of varying the dead state temperature should be analysed according to the operating data at different dead state temperature".

Laverge and Janssens [18] investigated heat recovery ventilation for different climates in Europe. They used exergy conversion factor (Carnot efficiency) as one of the indicators. The study showed that the heat recovery ventilation can be made profitable all over Europe.

Misevičiūte et al. [3] calculated the exergy demand for air heating in AHUs of the public building. Their research showed that it is possible to identify the outdoor temperature, when the exergy consumption is maximum. If this temperature is known the selection and optimisation of AHUs can be performed.

Zhang et al. [29] used exergy and entransy analysis to investigate HVAC systems in buildings. T- $Q$ (temperature-heat) diagrams were mainly used to analyse various heat exchangers. Authors showed that the entransy dissipation extremum principle was preferable for the optimisation of heat exchangers. The results of entransy analysis of HVAC systems was also presented in [30].

Kim et al. [31] evaluated the performance of various cooling systems using energy and exergy analyses. They showed that the decentralized ventilation system performed better compared to the central Air Handling Unit (AHU). Also authors concluded that the value of the exergy efficiency was influenced by the ambient thermal conditions.

Khalid et al. [32] analysed three HVAC systems using renewable energy sources to determine the effects of various parameters including ambient temperature, on the energy and exergy efficiencies. Heat pump was one of the few HVAC system components analysed in this study. The energetic COP and exergetic COP were calculated at variable ambient temperature between $+25^{\circ} \mathrm{C}$ and $+40^{\circ} \mathrm{C}$. The results of the study show that the exergetic COP decreases significantly from 0.22 to 0.004 depending 
on the environment temperature, while the energetic COP remains constant. The authors also found that main components responsible for large amount of exergy destruction were evaporators.

The concept of exergy can also be used for the optimisation of energy systems. Jain and Alleyne [33] designed an optimal controller for a four-component vapour compression system using the exergy approach. It allowed the maximization of exergy efficiency while achieving required cooling capacity.

Du et al. $[34,35]$ proposed Control Perfect Index ranking method to evaluate the control of HVAC systems. According to the researchers this approach could provide more information for the users on the selection of optimal strategy. Razmara et al. [36] developed Model Predictive Control technique using exergy model to minimize the exergy destruction in HVAC system. A method based on the exergy analysis, to set up an ideal operation of HVAC system was presented by Fang et al. [6]. Using this optimisation technique they calculated the ideal exergy destruction of each HVAC subsystem.

Exergy efficiency is the most often used exergy-based parameter, when different energy conversion systems are compared. The exergy efficiency indicator is more informative than the energy efficiency value. It is more useful when system imperfections have to be identified or analysing how systems could be improved [26]. There are two definitions of exergy efficiency used in exergy analysis $[17,19,37-40]$ :

- Universal (input-output, brute-force, overall or total) exergy efficiency, which is defined as the ratio of all outgoing to incoming exergy flows;

- Functional (utilitarian, consumed-produced, rational or task) exergy efficiency, which is defined as the ratio of to the system generated (produced) and given (consumed) exergy.

From the literature review above it is clear that exergy analysis is a valuable methodology. The results of the exergy analysis depend on the selection of the reference temperature. If the reference temperature is variable, new exergy analysis methods could be developed to evaluate dynamic behaviour of HVAC systems. In this study the exergy analysis methodology for evaluation of Air Handling Units, based on the approach developed for heat exchangers reported in previous publications $[23,41]$ is presented. The novelty of this study is the use of variable reference temperature, which is equivalent to environment temperature. This approach allows the calculation of thermodynamic indicators, such as: Coefficient of Performance (COP), universal and functional exergy efficiencies as well as exergy destruction in AHU components at variable reference temperatures. In this study four AHUs have been analysed and compared using the new methodology. The effect of integration of Heat Pump (HP) and Heat Recovery Exchanger (HRE) into AHU on the exergy efficiency has been investigated using the indicators presented above. The proposed 
methodology and results obtained from this study could be used for the selection of optimal AHUs, design more efficient HVAC systems, and could be used for the development of dynamic HVAC system models.

\section{Universal and functional exergy efficiencies of AHU}

To ensure better living and working conditions in buildings it is imperative to create suitable thermal comfort by heating, cooling and conditioning of supply air. This is usually achieved using AHUs. It is assumed that AHUs are designed to supply required amount of fresh air at a suitable temperature. In this section the exergy methodology developed for analysis of AHUs taking into account the variation of reference temperature is presented.

AHU is a multicomponent device consisting of different components, such as: fans, heat exchangers, humidifiers etc. Typical diagram of mass and energy flows in AHU is shown in Figure 1.

[Figure 1]

It is assumed that air mass flow rate for ventilation, $\dot{M}_{V}$ (it is assumed constant), supply and extract air temperatures to and from the room $T_{R}$ and outside air temperature $T_{e}$ are chosen to be independent variables. Exhaust air temperature after AHU is $T_{E}$. To conduct the exergy analysis the reference temperature should be chosen. Since the outside air temperature varies it is assumed that the reference temperature also varies and it is identical to the outside air temperature $T_{e}$.

AHU can be equipped with different components, which are chosen according to the requirements. To compare the effectiveness of different AHU two thermodynamic parameters, including Coefficient of Performance (COP) and exergy efficiency can be used. The COP of AHU is calculated similarly as for Heat Pump (HP):

$$
C O P_{A H U}=\frac{\dot{Q}_{A H U}}{\dot{E}_{A H U}^{+}},
$$

Here, $\dot{E}_{A H U}^{+}$is the exergy flow rate supplied to AHU components, such as: fans for transportation of air, HP compressors and to heat transfer devices (electric heaters or Water-to-Air heat exchangers WAH). $\dot{Q}_{A H U}$ is heat flow rate required to ensure that air is supplied at the desired temperature. Heat flow rate is calculated using equation:

$$
\dot{Q}_{A H U}=\dot{M}_{V} c_{p a}\left(T_{R}-T_{e}\right) \text { or } q_{A H U}=h_{R}-h_{e}=c_{p a}\left(T_{R}-T_{e}\right)
$$

Another useful thermodynamic parameter is exergy efficiency. AHUs can be assessed and compared using two exergy efficiency parameters: 
- Universal exergy efficiency;

- Functional exergy efficiency.

The universal exergy efficiency is calculated as the ratio of all outgoing and incoming exergy streams. The functional exergy efficiency is the ratio of transferred (produced) and consumed exergy in the particular component or system.

To explain the differences between universal and functional exergy efficiency calculation methods an example of a simple isolated heat exchanger is used (Figure 2). It is assumed that the mass flow rates and specific heats of fluids are the same. Flow 1-2 is "cold" stream, and flow 3-4 is "hot" stream.

[Figure 2]

Equations used to calculate the universal and functional exergy efficiency are provided in Table 1. Exergy streams and values of "produced" and "consumed" exergy used for calculation of universal and functional efficiencies are computed taking into account variable reference conditions. From the point of view of thermodynamics the destroyed exergy $l_{\Sigma}$ cannot and does not depend on how the exergy efficiency is calculated.

[Table 1]

It has been reported in previous studies that the universal and functional exergy efficiencies can be calculated using coenthalpies $[41,42]$. Using this approach, the coenthalpy of the working fluid at state $i$ can be calculated:

$$
k_{i}=h_{i}-T_{e} s_{i}=c_{p}\left(T_{i}-T_{e} \ln \frac{T_{i}}{273.15}\right)
$$

Here the enthalpy is defined as $h_{i}=c_{p} T_{i}$, entropy is $s_{i}=c_{p} \ln \frac{T_{i}}{273.15}$ and $T_{e}$ is the reference temperature.

Coenthalpy $k_{e}$ at reference temperature $T_{e}$ is calculated:

$$
k_{e}=T_{e} c_{p}\left(1-\ln \frac{T_{e}}{273.15}\right)
$$

Using coenthalpies the exergy of a stream can be calculated:

$$
e_{i}=k_{i}-k_{e}=\left(h_{i}-h_{e}\right)-T_{e}\left(s_{i}-s_{e}\right)
$$

The exergy change during any process is calculated as the difference of coenthalpies at states 1 and 2. 


$$
e_{12}=k_{1}-k_{2}=\left(h_{1}-h_{2}\right)-T_{e}\left(s_{1}-s_{2}\right)
$$

Thus, using coenthalpy the exergy destruction in the heat exchanger is calculated:

$$
l_{\Sigma}=k_{1}+k_{3}-k_{2}-k_{4}
$$

For simplified AHU shown in Figure 1, coenthalpy can be used to calculate the universal and functional exergy efficiencies. Equations 3 and 4 are used to calculate coenthalpy $k_{R}$ of room air, coenthalpy $k_{E}$ of exhaust air and coenthalpy $k_{e}$ of the outside air. Specific exergy $e^{ \pm}=\sum \dot{E} / \dot{M}_{V}$ is defined as an external exergy stream crossing thermodynamic system boundaries of AHU. This exergy stream is not directly related to air flow, but it is associated with the electrical or thermal energy required for transportation of air (fans), operation of HP or preheating of air in WAH exchangers or for electric heaters. The exergy is not generated in AHU ( $\left.e^{-}=0\right)$, but can only be used $\left(e^{+} \neq 0\right)$. When the exergy is transferred to air from another working fluid, for example in WAH, the exergy crossing the system boundaries is calculated using equation:

$$
e^{+}=\frac{\dot{M}_{W}}{\dot{M}_{V}}\left(k_{W i n}-k_{W o u t}\right),
$$

Then, the universal and functional exergy efficiencies of AHU can be calculated using equations provided in Table 2 .

[Table 2]

\section{Description of analysed AHU}

In this study four types of AHUs have been investigated (Figure 3). All systems are equipped with air supply fan Fs (1) and exhaust air fan Fe (2). In AHU 1 (Figure 3a) fresh air is taken at the environment temperature and after the heating in water-to-air (WAH) heat exchanger (3) it is supplied to the building. In AHU 2 (Figure 3b) the fresh air at the environment temperature is first preheated in heat recovery exchanger (HRE) (4). Further heating of air occurs in WAH (3).

[Figure 3]

AHU 3 (Figure 3c) has two fans $(1,2)$ and a heat pump (HP). The HP consists of compressor (CM) (5), throttle valve (TV) (6) and two heat exchangers - condenser (CN) (7) and evaporator (EV) (8). The HP operates on a vapour compression refrigeration cycle. In this AHU the fresh air is heated to required temperature in $\mathrm{CN}(8)$ and transported to the building. In EV (8) the refrigerant evaporates due to relatively high temperature of the exhaust air. AHU 4 (Figure 3d) has two fans $(1,2)$, HP and 
it is equipped with a HRE (4). In this system the fresh air is first preheated in HRE (4) and then heated to required temperature in $\mathrm{CN}(7)$.

From Figure 3 it is seen that the thermal energy can be transferred using simple WAH exchanger, HRE or condensers (CN) (7) and evaporators (EV) (8). AHUs usually operate at different, but narrow range of temperatures, and thermodynamic processes in all heat exchangers (WAH, HRE, CN, EV) are similar. Energy balance equations for these heat exchangers are given below.

Energy balance equation for simple WAH:

$$
\dot{Q}_{W A H}=\dot{M}_{W} c_{p W}\left(T_{W i n}-T_{W o u t}\right)=\dot{M}_{V} c_{p a}\left(T_{K}-T_{c}\right) \text { or } q_{W A H}=\frac{\dot{M}_{W}}{\dot{M}_{V}}\left(h_{W i n}-h_{W o u t}\right)=h_{K}-h_{c}=c_{p a}\left(T_{K}-T_{c}\right)
$$

Here $\dot{M}_{W}$ is water mass flow rate in WAH.

Energy balance equation for HRE is:

$$
\dot{Q}_{H R E}=\dot{M}_{V} c_{p a}\left(T_{h}-T_{w}\right)=\dot{M}_{V} c_{p a}\left(T_{c}-T_{e}\right) \quad \text { or } \quad q_{H R E}=h_{h}-h_{w}=h_{c}-h_{e}=c_{p a}\left(T_{c}-T_{e}\right)
$$

When heat pumps are used two additional heat exchangers have to be analysed. Energy balance of the condenser is:

$$
\dot{Q}_{C N}=\dot{M}_{r e f r}\left(h_{2}-h_{4}\right)=\dot{M}_{V} c_{p a}\left(T_{K}-T_{c}\right) \quad \text { or } \quad q_{C N}=\frac{\dot{M}_{r e f r}}{\dot{M}_{V}}\left(h_{2}-h_{4}\right)=h_{K}-h_{c}=c_{p a}\left(T_{K}-T_{c}\right)
$$

Here $\dot{M}_{\text {refr }}$ is flow rate of refrigerant in HP. Refrigerant R410a is used for this study.

Energy balance of the evaporator:

$$
\dot{Q}_{E V}=\dot{M}_{r e f r}\left(h_{1}-h_{5}\right)=\dot{M}_{V} c_{p a}\left(T_{w}-T_{E}\right) \quad \text { or } \quad q_{E V}=\frac{\dot{M}_{r e f r}}{\dot{M}_{V}}\left(h_{1}-h_{5}\right)=h_{w}-h_{E}=c_{p a}\left(T_{w}-T_{E}\right)
$$

It is assumed that the temperature of the inlet air to the HRE is the same as that of outside air temperature $T_{e}$. Then the effectiveness of the heat exchangers is calculated using equations:

$$
\varepsilon_{T}=\frac{T_{h}-T_{w}}{T_{h}-T_{e}} \quad(12 \mathrm{a}) \text { or } \quad \varepsilon_{T}=\frac{T_{c}-T_{e}}{T_{h}-T_{e}}
$$


For AHU 1 and AHU 2 systems the specific exergy crossing the system boundaries $\left(e^{ \pm}\right)$is positive and is calculated using equation:

$$
e^{+}=\frac{\dot{M}_{W}}{\dot{M}_{V}}\left(k_{W i n}-k_{W o u t}\right)+e_{F s}+e_{F e},
$$

Here $k_{\text {Win }}, k_{\text {Wout }}$ are specific inlet and outlet coenthalpies of working fluid in WAH; and $e_{F s}, e_{F e}$ specific exergies required for fans. If electrical heater is used the specific exergy crossing system boundaries is calculated by replacing the coenthalpy difference and mass ratio product in equation 13 with specific exergy required for the heater.

Specific exergy for AHU 3 and 4 systems is calculated using equation:

$$
e^{+}=e_{C M}+e_{F s}+e_{F e}
$$

Here $e_{C M}$ is specific exergy required for the compressor, $\mathrm{kJ} / \mathrm{kg}$.

To calculate the universal and functional exergy efficiencies, exergy flows and exergy destruction of different AHU equations given in Table 2 are used. These expressions are useful for calculation of exergy efficiency at variable reference temperatures.

In this study the following assumptions have been made:

1. Room and outside air is dry air, and the mass flow rates of supply and exhaust air streams are the same.

2. AHU is well insulated, and energy is transferred to the system through air heaters (exchangers) and fans.

3. Fan power is chosen based on the recommended value for HVAC systems (in $\mathrm{W} / \mathrm{m}^{3} / \mathrm{s}$ ).

4. There are no additional heat sources in the room.

5. It is assumed that mass flow rate $\dot{M}_{V}$ and room temperature $T_{R}$ are the same for all AHUs. Heat required to preheat air is calculated using equation 2. Parameters used for comparison of AHUs are: COP, universal exergy efficiency and functional exergy efficiency. All calculations are based on the data given in Table 3.

[Table 3]

To compare different AHUs the same temperature of the working fluid has been used. Thus, supply and return temperatures of the working fluid in WAH (3) (for AHU 1 and 2, Figure 3) and in HP condenser ( 7 in Figure 3) (for AHU 3 and AHU 4) are the same, $75^{\circ} \mathrm{C}$ and $30^{\circ}$ respectively. The 
maximum $75^{\circ} \mathrm{C}$ temperature in $\mathrm{HP}$ is achieved after the compressor (5, Figure 3), and the condensation takes place at a constant $30^{\circ} \mathrm{C}$. Pressure-enthalpy diagram of HP cycle using R410a as a refrigerant is shown in Figure 4. Red line 2-3-4 represents cooling and condensation at a constant pressure in the condenser (7). The red line 5-1 shows the evaporation process which occurs in the evaporator (8) at a constant temperature of $-30^{\circ} \mathrm{C}$. Red lines 1-2-4-5 represent the HP cycle of AHU 3 and AHU 4 systems with constant compressor speed.

[Figure 4]

AHU 4, which is controlled using advanced HP control algorithm also has been analysed. In this case when the speed of the compressor (5) reduces to a minimum the compression pressure varies and the evaporation and condensation temperatures can change. Such modified HP cycle is shown using blue lines 1-2-4-5 (Figure 4). All parameters of this advanced system (labelled AHU4R) can change between the red and blue cycles.

For all AHUs with HP it is assumed that there is no subcooling in the condenser (7) or superheating in the evaporator (8). All calculations have been conducted using equations provided above.

\section{Results and discussions}

In the first part of this section the calculations of effectiveness of AHUs using thermodynamic (exergy) analysis methods are presented and discussed. From equation 1 it is seen that the COP of AHU is calculated as the ratio of the heat flow rate and the exergy flow rate supplied to AHU components. If only electrical air heaters are used the exergy flow rate is equal to electricity consumption. However, when WAH (3) is used the exergy supplied to AHU should be calculated taking into account the temperatures of working fluid.

In the second part of this section the exergy-based indicators: universal exergy efficiency and functional exergy efficiency are presented (Table 2). These indicators depend on the environment (reference) temperature, and one of the aims of this study is to present the methodology suitable for evaluation of AHUs using variable environment (reference) temperature.

Four AHUs, seven different cases have been analysed and compared:

- AHU 1 with WAH (AHU1);

- $\quad$ AHU 2 with WAH and HRE at $\varepsilon_{T}=60 \%$ (AHU2-60);

- $\quad$ AHU 2 with WAH and HRE at $\varepsilon_{T}=70 \%$ (AHU2-70);

- $\quad$ AHU 2 with WAH and HRE at $\varepsilon_{T}=80 \%$ (AHU2-80);

- $\quad$ AHU 3 with HP (AHU3); 
- $\quad$ AHU 4 with HP and HRE at $\varepsilon_{T}=70 \%$ (AHU4-70);

- $\quad$ AHU 4 with HP and HRE at $\varepsilon_{T}=70 \%$, using advanced HP control (AHU4R-70).

The results of COP calculated in Equation 1 for different AHUs at different reference temperatures are provided in Figure 5. It is seen from the graph that for AHU1 the COP is slightly below 1, and that for AHUs without HRE and HP no significant improvement in efficiency can be achieved.

[Figure 5]

The value of COP of AHU2-70 is around 3 (Figure 5). For AHU2-80 the COP almost reaches 5, and for AHU2-60 the COP is around 2.2. Significantly higher COP of AHUs with HRE is achieved due to the lower amount of energy (and exergy) transferred from external source. For AHU1 and AHU2 systems a small reduction of COP is observed at higher reference temperatures.

For AHU3, which is equipped with HP without HRE, the value of the COP is around 3. Clearly, this COP value depends on the COP value of the HP. It means that when only HP is used, the efficiency of the AHU can be even lower than that of the simple AHU with HRE (AHU2-70 or AHU2-80). The use of such a system should be considered only in those cases when a more compact AHU is required.

Two COP curves of AHU4 and AHU4R, which are equipped with HP and HRE, are shown by green lines in Figure 5. Using HRE with $\varepsilon_{T}=70 \%$ and constant evaporation and condensation pressures (these processes are shown as red lines 2-4 for the evaporator and 5-1 for the condenser in Figure 4) the COP of AHU4-70 is considerably higher at all reference temperatures compared to AHU1, AHU2 and AHU3. The increase of the COP could be explained due to the synergistic effect of the HP and $\mathrm{HRE}$, and because the WAH in this $\mathrm{AHU}$ is not used. At reference temperature of around $-35^{\circ} \mathrm{C}$ the COP of AHU4 and AHU4R is about 9.5 (not shown in the figure). Considerably higher COP is observed when advanced control method of HP in AHU4R is used at higher reference temperatures. Due to the increase of the environment (and reference) temperature the heat demand reduces linearly (Equation 2). By varying speed of the compressor, lower pressure and temperature difference between the evaporator and condenser can be achieved. The change of the pressure difference between the evaporator and the condenser can be observed in Figure 4 (red lines 2-4 and 5-1 are approaching the blue lines 2-4 and 5-1). As a result, the electricity consumption of the compressor decreases and the COP of the HP increases. It can be seen from Equation 1 the change of the heat demand (numerator) is slower compared to the change of the exergy flow rate for the fans and compressor (denominator). The fan speed (and electricity consumption) is constant for all cases. Therefore, due the lower energy consumption in the compressor the COP of AHU4R is higher than that of AHU4. The COP of AHU4R reaches its maximum at reference temperatures of around $0^{\circ} \ldots+5^{\circ} \mathrm{C}$. For the temperatures above those values the COP of AHU reduces, because the power consumption by fans remains higher compared 
to the power consumption by the compressor. Less pronounced effect of power consumption by fans on the COP can also be seen for other cases (Figure 5).

Variation of universal and functional exergy efficiencies of AHU depending on the reference temperature are shown in Figure $6 \mathrm{a}$ and $6 \mathrm{~b}$.

[Figure 6]

It is seen from the graph that the universal exergy efficiency of AHU1 and AHU2-60 is almost the same. It is expected that if the supply temperature is reduced and the mass flow rate of water supplied to WAH is increased in AHU1 the exergy efficiency can exceed the efficiency of AHU2-60. It means that for the same heat demand the amount of exergy transferred will reduce. The universal exergy efficiency, $\eta_{U}$, of AHU3 (only HP) is considerably lower compared to all AHU1, AHU2 and AHU4. This shows the importance of using HRE in HVAC applications.

Interesting results can be observed when comparing AHU2-70 with AHU4-70 and AHU4R-70, which have the same HRE efficiency of $\varepsilon_{T}=70 \%$. The efficiency of AHU4-70 remains significantly lower at all reference temperatures compared to AHU2-70 and AHU4R-70. The universal exergy efficiency of AHU2-70 is higher than that of AHU4R-70 at lower reference temperatures. However, at reference temperature of around $-7^{\circ} \mathrm{C}$ and above, $\eta_{U}$ drops below the efficiency of AHU4R-70. This is due to the variation of temperatures (and pressures) in the evaporator and condenser of AHU4R-70. In the AHU4R-70 the variation of the universal exergy efficiency $\eta_{U}$ is less susceptible to the variations of reference temperature, and from thermodynamic point of view the AHU4R-70 is more advantageous compared to AHU2-70.

For AHU3 and AHU4 the values of the $\mathrm{COP}_{\mathrm{AHU}}$ (Figure 5) and the exergy efficiency (Figure 6) depend on the performance of HP. Although in both AHUs the COP of HP is higher than 1, the exergy efficiency of those systems is always below 1. This is due to the low thermal exergy that is obtained from the high exergy electricity in the HP. The thermal exergy is calculated using conversion factor (Carnot efficiency), which depends on the environment temperature $\left(1-T_{e} / T_{i}\right)$.

Functional exergy efficiency of AHUs is shown in Figure 6b. It is clear that the values of the universal and functional exergy efficiency for AHU1 differs considerably. Functional exergy efficiency for this system decreases from $32 \%$ to $9 \%$, and the universal exergy efficiency changes from $49 \%$ to $18 \%$ when the reference temperature increases from $-30^{\circ} \mathrm{C}$ to $+10^{\circ} \mathrm{C}$. Similar trend $\left(\eta_{F}<\eta_{U}\right)$ is observed for all schemes, and the difference between the universal and functional efficiency depends on the reference temperature. This difference is smaller for AHU3 and AHU4 systems, which are equipped with HP. 
Also, when AHU2-70, AHU4-70 and AHU4R-70 are compared, it is seen that the change of the functional exergy efficiency is similar to the change of the universal exergy efficiency. The functional exergy efficiency of AHU4-70 remains significantly lower at all reference temperatures compared to AHU2-70 and AHU4R-70, and the functional exergy efficiency of AHU4R-70 exceeds the exergy efficiency of AHU2-70 at reference temperatures above $-14^{\circ} \mathrm{C}$.

It is worth mentioning that the functional exergy efficiency is more sensitive to the variation of the thermal effectiveness of HRE. For instance, the universal exergy efficiency varies between $38 \%$ and $48 \%$ and the functional exergy efficiency is in the range from $23 \%$ to $47 \%$ for AHU without HP (AHU1 and all AHU2) at reference temperature of $T_{e}=-10^{\circ} \mathrm{C}$. Thus, the functional exergy efficiency is more informative compared to the universal exergy efficiency, although the difference between these parameters is less noticeable for AHU with HP.

The use of universal and functional exergy efficiency indicators in this study contributes to the knowledge about these exergy-based parameters. It has been shown above that the universal exergy efficiency is less sensitive and has limited applicability compared to the functional exergy efficiency. For example, using functional exergy efficiency (Figure 6b) it becomes clear that AHU1 is less advantageous compared to other AHUs, while using the universal exergy efficiency (Figure 6a) it is not so obvious. Similar behaviour of universal and functional exergy efficiencies in other thermodynamic systems have been observed and discussed by other researchers [37, 39].

One of the most important parameters in thermodynamic analysis is exergy destruction. The variation of the exergy destruction as a function of the reference temperature is shown in Figures 7, 8 and 9. The highest amount of exergy destroyed is observed for AHU3 and AHU1 (Figure 7). For AHU3 (with HP only) the high quality energy (electricity) is converted to a low quality thermal energy. For AHU1 (with WAH only) the exergy destruction depends also on the temperature of the heat carrier (water). For all AHUs that have HRE, especially for those with high $\varepsilon_{T}$, the exergy destruction is much lower. These results indicate the importance of HRE. Moreover, using AHU4R with advanced HP control, the performance of AHU can be improved considerably. It is worth mentioning that when comparing AHUs, it is important to use this thermodynamic analysis methodology consistently taking into account the variation of reference temperature in order to obtain comparable results.

[Figure 7]

More detailed analysis of exergy destruction in each component of the AHU3 and AHU4-70 with HP is provided in Figures 8 and 9. Figure 8 shows the exergy destruction in the components of AHU3 (with HP only). It is seen that the exergy destruction reduces when the reference temperature 
increases. The highest exergy destruction is observed in the condenser at reference temperatures between $-30^{\circ} \mathrm{C}$ and $-18^{\circ} \mathrm{C}$. At reference temperature above $-18^{\circ} \mathrm{C}$, more exergy is destroyed in the evaporator than in the condenser. The exergy destruction in the supply and exhaust air fans remains almost constant (Figure 8a). However, due to the decrease of overall exergy destruction in AHU3, the share of the exergy destruction in the fans increases from around $4 \%$ to $18 \%$ at higher reference temperatures (Figure 8b). Relative exergy destruction (Figure 8b) in the compressor (14\%) and throttle valve (16-17\%) remains almost the same for all reference temperatures. The relative exergy destruction in the condenser reduces from around $37 \%$ to $15 \%$, when the reference temperature increases.

[Figure 8]

[Figure 9]

It is worth mentioning that the exergy destruction is only one of several exergy-based parameters, and the exergy supplied for different AHUs is different. However, the information about the exergy destruction in AHU components at variable environment (reference) temperatures is valuable and could contribute to the improvement of HVAC systems.

The exergy destruction in the components of AHU4-70 is shown in Figure 9. It is seen that the exergy destruction in $\mathrm{HRE}$ varies from $0.36 \mathrm{~kW}$ at $-30^{\circ} \mathrm{C}$ to $0.02 \mathrm{~kW}$ at $+10^{\circ} \mathrm{C}$. The main reason of high exergy destruction in the HRE at low reference temperature is large temperature difference between the temperature of supplied and exhaust air. More detailed exergy analysis of HRE can be found in previous studies $[23,41]$.

The overall relative exergy destruction in the HP components: compressor, throttle valve, evaporator and condenser varies between $50 \%$ and $59 \%$ depending on the reference temperature. In the compressor, valve and condenser the exergy destruction reduces from $42 \%$ to $28 \%$ when the reference temperature increases. However, the share of the exergy destruction in the evaporator increases significantly. As it was previously mentioned, the relative exergy destruction in the fans increases from around $13 \%$ to $45 \%$, when the reference temperature changes from $-30^{\circ} \mathrm{C}$ to $+10^{\circ} \mathrm{C}$. It is worth noting that the power consumption for the fans is constant in this study.

The discussion confirms that the operation of HVAC systems depends on the climate conditions, and especially on the environment temperature. In thermodynamic analysis the exergy flow rates also depend on the environment (reference) temperature, which is usually assumed to be constant. The methodology developed by the authors and presented in this study shows that all exergy based parameters, such as: the universal and functional exergy efficiencies, and absolute exergy destruction are very sensitive to the variation of the reference temperature. Therefore, the proposed methodology 
could be used for the analysis and improvement of HVAC systems that operate at variable environment temperatures, and also for the development of dynamic models of such systems.

\section{Conclusions}

Traditional exergy analysis used for evaluation of energy conversion systems has some limitations as the reference temperature (and pressure) is fixed. The energy demand of HVAC systems depends on the temperature of the environment, which varies during the season and could be below, above or equal to the operating temperature of the working fluids. Therefore, to analyse AHUs the method for calculating of exergy efficiency at variable reference temperature has been used in this study.

This study aims to compare four AHUs using the thermodynamic parameters including COP, universal exergy efficiency and functional exergy efficiency, taking into account the variable reference temperature in the range from $-30^{\circ} \mathrm{C}$ to $+10^{\circ} \mathrm{C}$. The main conclusions of this study are:

1. When performing exergy analysis of HVAC systems variable reference temperature should be used. This approach allows obtaining detailed data on the efficiency of the system components and its variation depending on the variable environment temperature. Thermodynamic parameters, including universal and functional exergy efficiency and exergy destruction values, clearly show which AHU system is more efficient at different environment temperatures. This information allows further development of calculation algorithms for determining the seasonal performance of HVAC systems.

2. The effectiveness of HRE has the most prominent effect on the COP, the universal and functional exergy efficiencies. Special care should be taken when selecting suitable HRE for AHU and the variation of the reference temperature should be taken into account.

3. The COP of AHU, which is equipped with HP only (AHU3), is lower than that of AHU with WAH and HRE (AHU2), and is significantly lower compared with AHU which has HP and HRE (AHU4). The AHU with HP only has the lowest universal and functional exergy efficiencies. Such system should only be used in the cases where the thermodynamic efficiency is not a priority and the compactness of the AHU is important.

4. For AHUs the difference between the values of universal and functional exergy efficiencies is small. The functional exergy efficiency is more informative compared to the universal exergy efficiency, although the difference between these parameters is less noticeable for AHUs with HP. Also, the functional exergy efficiency is more sensitive to the variation of the thermal effectiveness of HRE. 
5. The use of constant speed (power) fans in AHU is one of the factors that affect the COP or the exergy efficiency at variable environment (reference) temperature.

6. For AHU with HP, HRE and with advanced control method, the variation of the universal and functional exergy efficiency is less susceptible to the variation of the reference temperature. Therefore, such AHU is more advantageous compared to other AHUs.

\section{Acknowledgements}

This research was funded by a grant (No. MIP-077/2015) from the Research Council of Lithuania.

\section{Nomenclature}

Abbreviations

\begin{tabular}{ll} 
AHU & Air handling unit \\
CM & Compressor \\
CN & Condenser \\
COP & Coefficient of performance \\
EV & Evaporator \\
Fe & Exhaust fan \\
Fs & Supply fan \\
HP & Heat pump \\
HRE & Heat recovery exchanger \\
HVAC & Heating, Ventilation, and Air Conditioning \\
TV & Throttle valve \\
WAH & Water-to-air heat exchanger \\
Variables & \\
$c_{p}$ & specific heat capacity, $\mathrm{kJ} / \mathrm{kg} \mathrm{K}$ \\
$e$ & specific exergy, $\mathrm{kJ} / \mathrm{kg}$ \\
$e^{ \pm}$ & specific external exergy crossing system boundaries, $\mathrm{kJ} / \mathrm{kg}$ \\
$\dot{E}$ & exergy flow rate, $\mathrm{kW}$ \\
$h$ & specific enthalpy, $\mathrm{kJ} / \mathrm{kg}$ \\
$k$ & specific coenthalpy, $\mathrm{kJ} / \mathrm{kg}$ \\
$l$ & specific destroyed exergy, $\mathrm{kJ} / \mathrm{kg}$ \\
\hline & specific entropy, $\mathrm{kJ} / \mathrm{kg} \mathrm{K}$ \\
&
\end{tabular}


Subscripts

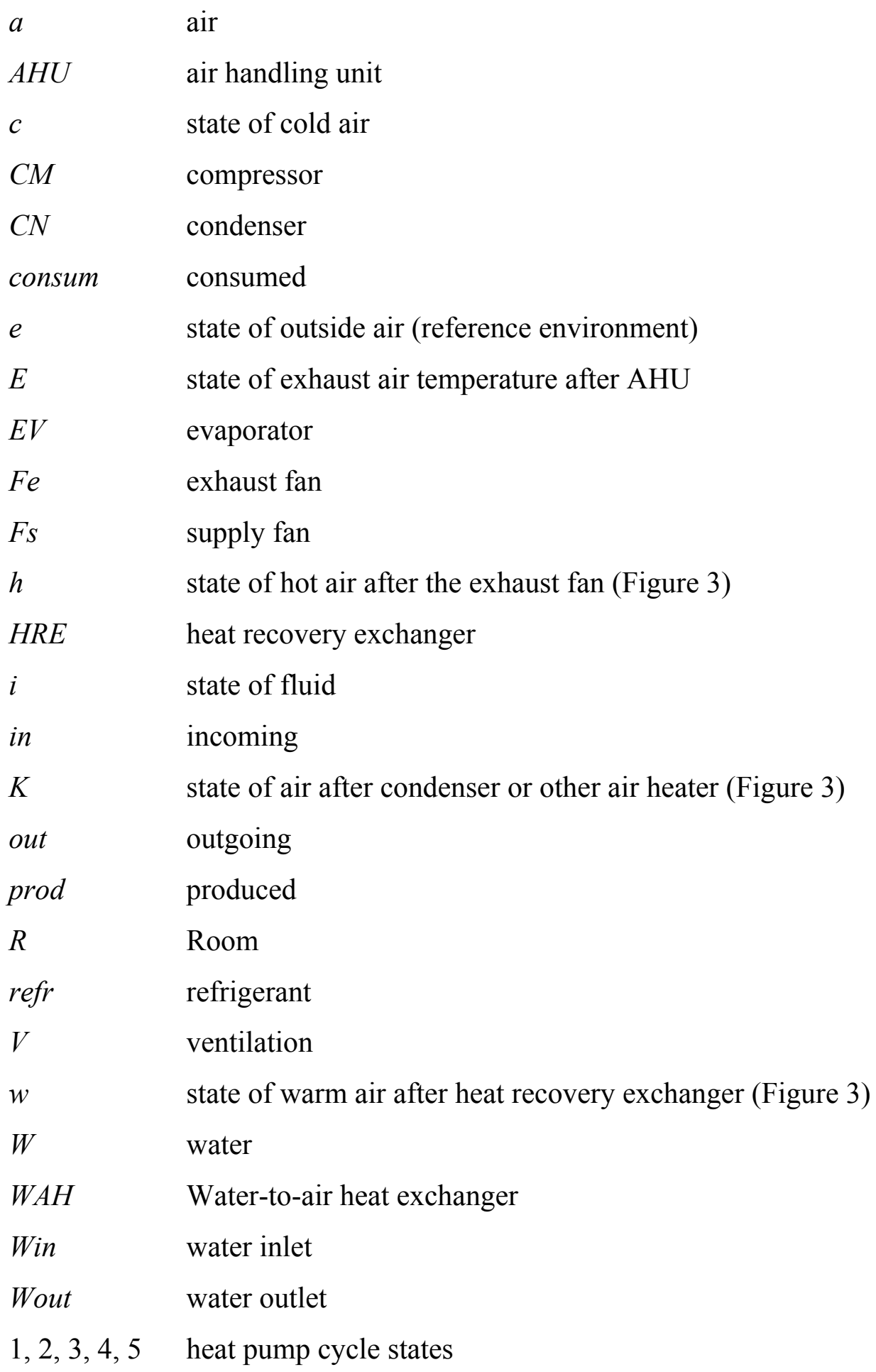




\section{Superscripts}

$+\quad$ to the system (supplied to the system)

- $\quad$ out of the system (leaving the system) 


\section{References}

[1] G. Evola, A. Gagliano, L. Marletta, F. Nocera, Controlled mechanical ventilation systems in residential buildings: Primary energy balances and financial issues, Journal of Building Engineering. 11 (2017) 96-107. doi:10.1016/j.jobe.2017.04.010.

[2] A. Mardiana-Idayu, S.B. Riffat, Review on heat recovery technologies for building applications, Renewable and Sustainable Energy Reviews. 16 (2012) 1241-1255. doi:10.1016/j.rser.2011.09.026.

[3] V. Misevičiūtè, K. Valančius, V. Motuzienè, G. Rynkun, Analysis of exergy demand for air heating of an air handling unit, Energy Efficiency. 10 (2017) 989-998. doi.org/10.1007/s12053-016-9499-7

[4] B. Chenari, J. Dias Carrilho, M. Gameiro Da Silva, Towards sustainable, energy-efficient and healthy ventilation strategies in buildings: A review, Renewable and Sustainable Energy Reviews. 59 (2016) 1426-1447. doi:10.1016/j.rser.2016.01.074.

[5] Y. El Fouih, P. Stabat, P. Rivière, P. Hoang, V. Archambault, Adequacy of air-to-air heat recovery ventilation system applied in low energy buildings, Energy and Buildings. 54 (2012) 29-39. doi:10.1016/j.enbuild.2012.08.008.

[6] X. Fang, X. Jin, Z. Du, Y. Wang, The evaluation of operation performance of HVAC system based on the ideal operation level of system, Energy and Buildings. 110 (2016) 330344. doi:10.1016/j.enbuild.2015.11.020.

[7] L. Wang, N. Li, B. Zhao, Exergy performance and thermodynamic properties of the ideal liquid desiccant dehumidification system, Energy and Buildings. 42 (2010) 2437-2444. doi:10.1016/j.enbuild.2010.08.022.

[8] M.A. Rosen, Assessing energy technologies and environmental impacts with the principles of thermodynamics, Applied Energy. 72 (2002) 427-441. doi:10.1016/S03062619(02)00004-1.

[9] I. Dincer, M.A. Rosen, Exergy Analysis of Heating, Refrigerating and Air Conditioning, 1 edition, Elsevier, 2015. doi:http://dx.doi.org/10.1016/B978-0-12-417203-6.00001-6.

[10] M.J. Moran, H. Shapiro, Fundamentals of engineering thermodynamics, 5th ed., Wiley, Chichester, 2006.

[11] I. Dincer. Comprehensive Energy Systems, Oshawa, Canada, Elsevier, 2018.

[12] D. Schmidt, H. Torío, ECBCS Annex 49. Low Exergy Systems for High-Performance Buildings and Communities, Kassel, 2011.

http://www.annex49.info/download/summary report.pdf. 
[13] P. Gonçalves, A.R. Gaspar, M.G. Da Silva, Comparative energy and exergy performance of heating options in buildings under different climatic conditions, Energy and Buildings. 61 (2013) 288-297. doi:10.1016/j.enbuild.2013.02.023.

[14] K. Sartor, P. Dewallef, Exergy analysis applied to performance of buildings in Europe, Energy \& Buildings. 148 (2016) 348-354. doi:10.1016/j.enbuild.2017.05.026.

[15] Z. Wei, R. Zmeureanu, Exergy analysis of variable air volume systems for an office building, Energy Conversion and Management. 50 (2009) 387-392. doi:10.1016/j.enconman.2008.09.010.

[16] V. Martinaitis, D. Bieksa, V. Miseviciute, Degree-days for the exergy analysis of buildings, Energy and Buildings. 42 (2010) 1063-1069. doi:10.1016/j.enbuild.2010.01.019.

[17] H. Torío, A. Angelotti, D. Schmidt, Exergy analysis of renewable energy-based climatisation systems for buildings: A critical view, Energy and Buildings. 41 (2009) 248271. doi:10.1016/j.enbuild.2008.10.006.

[18] J. Laverge, A. Janssens, Heat recovery ventilation operation traded off against natural and simple exhaust ventilation in Europe by primary energy factor, carbon dioxide emission, household consumer price and exergy, Energy and Buildings. 50 (2012) 315-323. doi:10.1016/j.enbuild.2012.04.005.

[19] A. Hepbasli, A key review on exergetic analysis and assessment of renewable energy resources for a sustainable future, Renewable and Sustainable Energy Reviews. 12 (2008) 593-661. doi:10.1016/j.rser.2006.10.001.

[20] S.R. Park, A.K. Pandey, V. V. Tyagi, S.K. Tyagi, Energy and exergy analysis of typical renewable energy systems, Renewable and Sustainable Energy Reviews. 30 (2014) 105123. doi:10.1016/j.rser.2013.09.011.

[21] D. Schmidt, Low exergy systems for high-performance buildings and communities, Energy and Buildings. 41 (2009) 331-336. doi:10.1016/j.enbuild.2008.10.005.

[22] F. Meggers, H. Leibundgut, The reference environment: utilising exergy and anergy for buildings, International Journal of Exergy. 11 (2012) 423-438. doi:10.1504/IJEX.2012.050254.

[23] V. Martinaitis, G. Streckiene, Concerning exergy efficiency evaluation of heat recovery exchangers for air handling units, Int. J. of Exergy. 20 (2016) 381-404.

[24] L. Zhang, X.H. Liu, Y. Jiang, Ideal efficiency analysis and comparison of condensing and liquid desiccant dehumidification, Energy and Buildings. 49 (2012) 575-583.

doi:10.1016/j.enbuild.2012.03.012. 
[25] M. Ghazikhani, I. Khazaee, S. Vahidifar, Exergy analysis of two humidification process methods in air-conditioning systems, Energy and Buildings. 124 (2016) 129-140. doi:10.1016/j.enbuild.2016.04.077.

[26] R. Chengqin, L. Nianping, T. Guangfa, Principles of exergy analysis in HVAC and evaluation of evaporative cooling schemes, Building and Environment. 37 (2002) 10451055. doi:10.1016/S0360-1323(01)00104-4.

[27] L. Wang, N. Li, Evaluation of buoyancy-driven ventilation in respect of exergy utilization, Energy and Buildings. 42 (2010) 221-229. doi:10.1016/j.enbuild.2009.08.019.

[28] J. Pu, G. Liu, X. Feng, Application of the cumulative exergy approach to different air conditioning systems, Energy and Buildings. 42 (2010) 1999-2004. doi:10.1016/j.enbuild.2010.06.007.

[29] L. Zhang, X. Liu, Y. Jiang, Application of entransy in the analysis of HVAC systems in buildings, Energy. 53 (2013) 332-342. doi:10.1016/j.energy.2013.02.015.

[30] S. Qian, L. Huang, V. Aute, Y. Hwang, R. Radermacher, Applicability of entransy dissipation based thermal resistance for design optimization of two-phase heat exchangers, Applied Thermal Engineering. 55 (2013) 140-148.

[31] M.K. Kim, H. Leibundgut, J.H. Choi, Energy and exergy analyses of advanced decentralized ventilation system compared with centralized cooling and air ventilation systems in the hot and humid climate, Energy and Buildings. 79 (2014) 212-222. doi:10.1016/j.enbuild.2014.05.009.

[32] F. Khalid, I. Dincer, M.A. Rosen, Development and analysis of sustainable energy systems for building HVAC applications, Applied Thermal Engineering. 87 (2015) 389-401. doi:10.1016/j.applthermaleng.2015.04.015.

[33] N. Jain, A. Alleyne, Exergy-based optimal control of a vapor compression system, Energy Conversion and Management. 92 (2015) 353-365. doi:10.1016/j.enconman.2014.12.014.

[34] Z. Du, X. Jin, B. Fan, Evaluation of operation and control in HVAC (heating, ventilation and air conditioning) system using exergy analysis method, Energy. 89 (2015) 372-381. doi:10.1016/j.energy.2015.05.119.

[35] Z. Du, X. Jin, X. Fang, B. Fan, A dual-benchmark based energy analysis method to evaluate control strategies for building HVAC systems, Applied Energy. 183 (2016) 700-714. doi:10.1016/j.apenergy.2016.09.019.

[36] M. Razmara, M. Maasoumy, M. Shahbakhti, R.D. Robinett, Optimal exergy control of building HVAC system, Applied Energy. 156 (2015) 555-565. doi:10.1016/j.apenergy.2015.07.051. 
[37] N. Woudstra, Woudstra.pdf, in: The Quality of Energy. In L. Stougie (Ed.), Energy Efficiency and the Quality of Energy in the Food Processing Industry, TU Delft/Interduct, Delft, The Netherlands, 2002: p. 125.

[38] N. Lior, N. Zhang, Energy, exergy, and Second Law performance criteria, Energy. 32 (2007) 281-296. doi:10.1016/j.energy.2006.01.019.

[39] D. Marmolejo-Correa, T. Gundersen, A comparison of exergy efficiency definitions with focus on low temperature processes, Energy. 44 (2012) 477-489.

doi:10.1016/j.energy.2012.06.001.

[40] T.V. Nguyen, M. Voldsund, B. Elmegaard, S.I. Ertesvåg, On the definition of exergy efficiencies for petroleum systems: Application to offshore oil and gas processing, Energy. 73 (2014) 264-281. doi:10.1016/j.energy.2014.06.020.

[41] V. Martinaitis, G. Streckienè, D. Biekša, J. Bielskus, The exergy efficiency assessment of heat recovery exchanger for air handling units, using a state property - Coenthalpy, Applied Thermal Engineering. 108 (2016) 388-397. doi:10.1016/j.applthermaleng.2016.07.118.

[42] L. Borel, D. Favrat, Thermodynamics and Energy Systems Analysis: From Energy to Exergy, EPFL Press, 2010. 


\section{List of figures}

Fig. 1. Mass and energy flow diagram of AHU.

Fig. 2. Simplified scheme of heat exchanger with indicated exergy streams.

Fig. 3. Analysed Air Handling Units (AHUs).

Fig. 4. Enthalpy-pressure diagram of HP cycles of AHU 3 and AHU 4 systems.

Fig. 5. Coefficient of Performance (COP) of AHU depending on reference temperature.

Fig. 6. Universal (a) and functional (b) exergy efficiency of AHU.

Fig. 7. Destroyed exergy for different AHU cases.

Fig. 8. Absolute exergy destruction (a), and relative exergy destruction (b) in the components of AHU3.

Fig. 9. Absolute exergy destruction (a), and relative exergy destruction (b) in the components of AHU4-70.

\section{List of tables}

Table 1. Universal and functional exergy efficiencies (see Figure 2).

Table 2. Universal and functional exergy efficiencies for AHU (see Figure 1).

Table 3. Data used in calculations. 


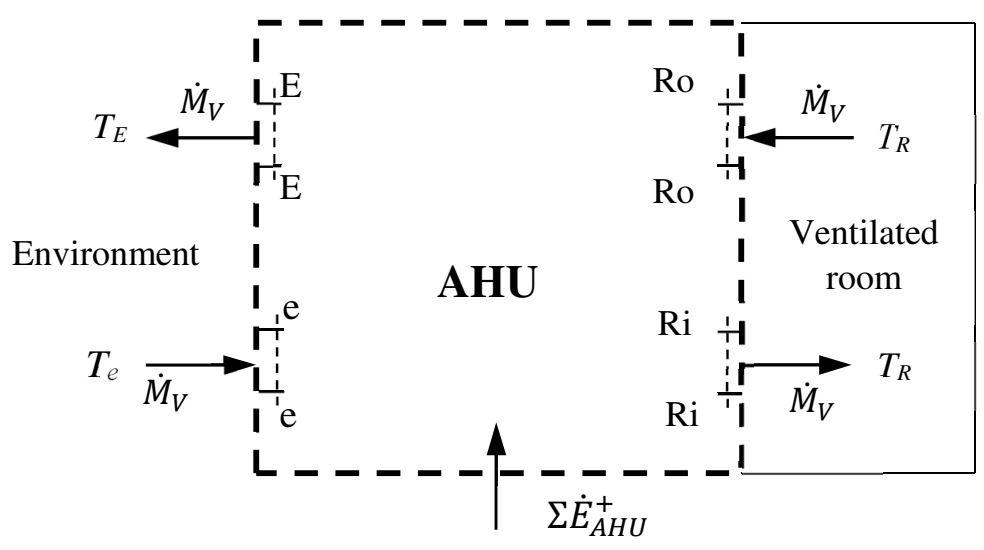

Fig. 1.

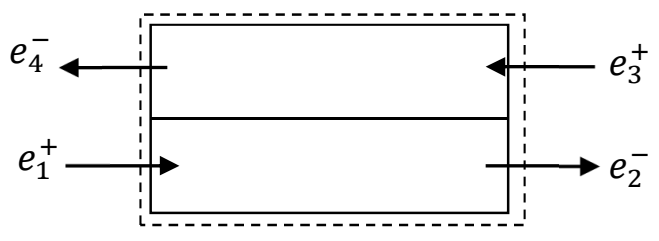

Fig. 2. 

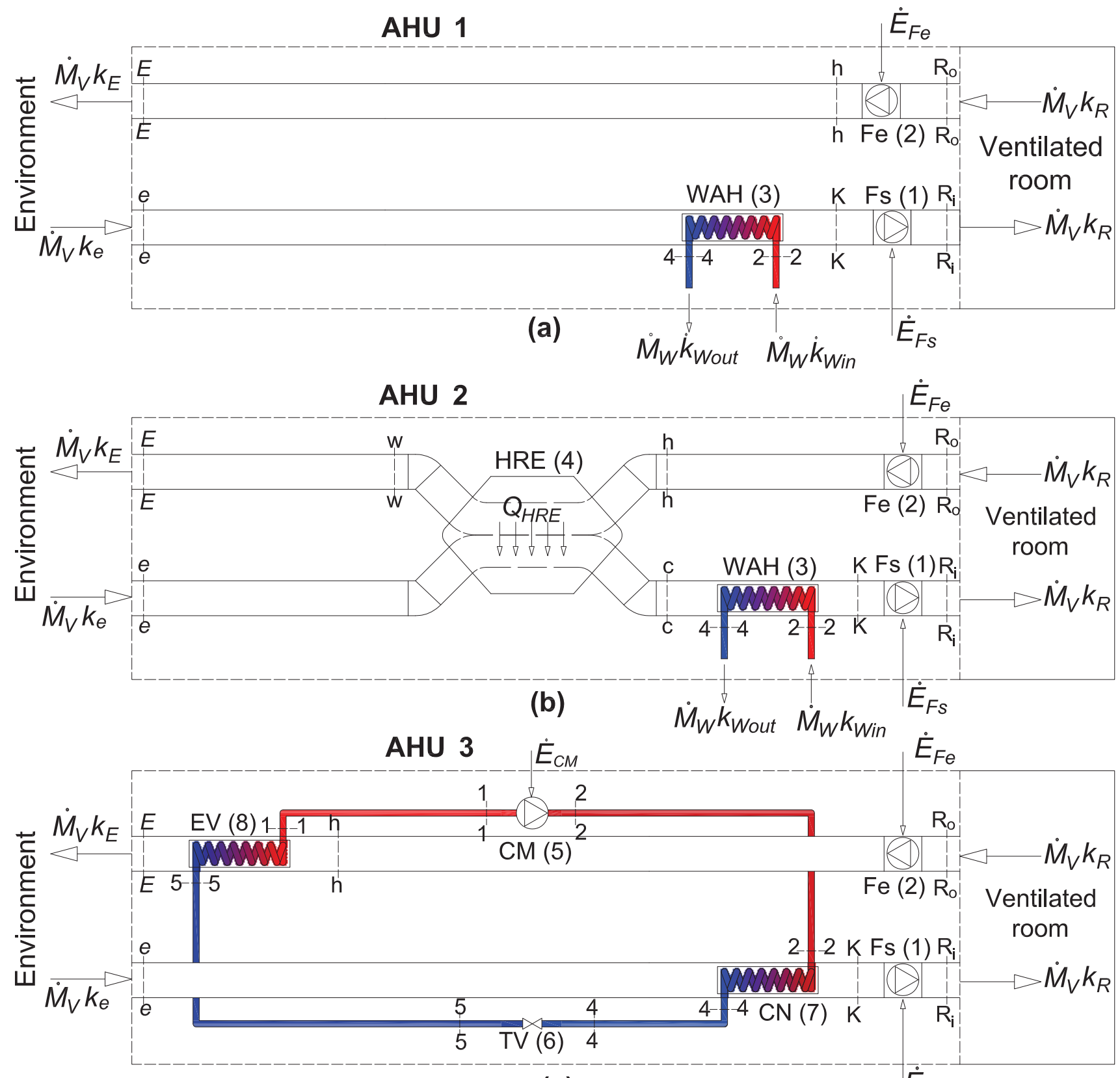

(c)

$\dot{E}_{F S}$

AHU $4 \quad \dot{E}_{C M} \quad \dot{E}_{F e}$

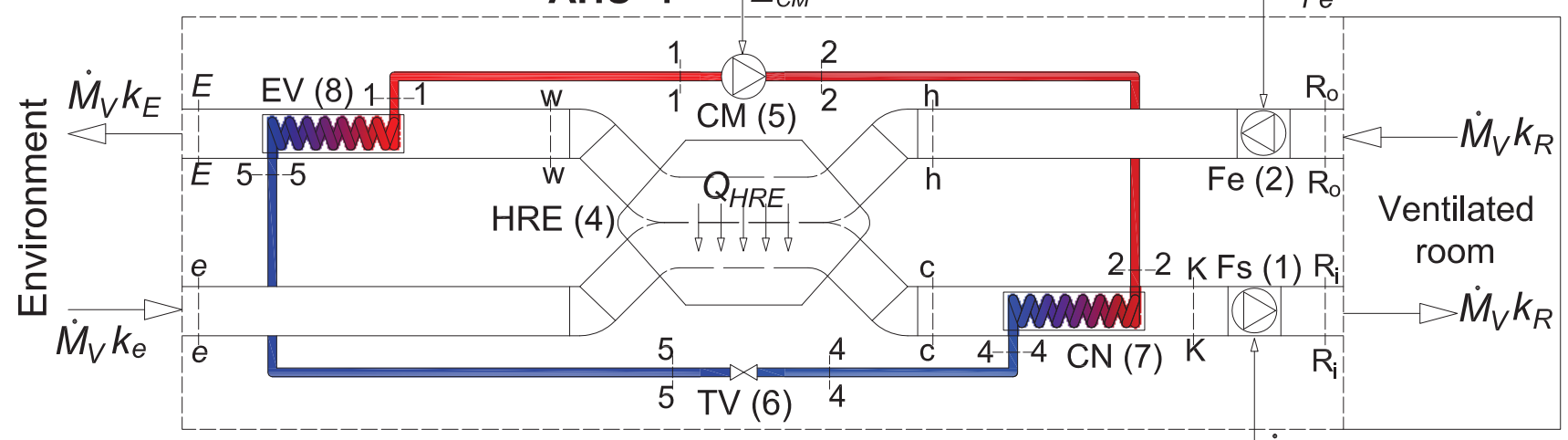

(d)

$\dot{E}_{F s}$

Fig. 3. 


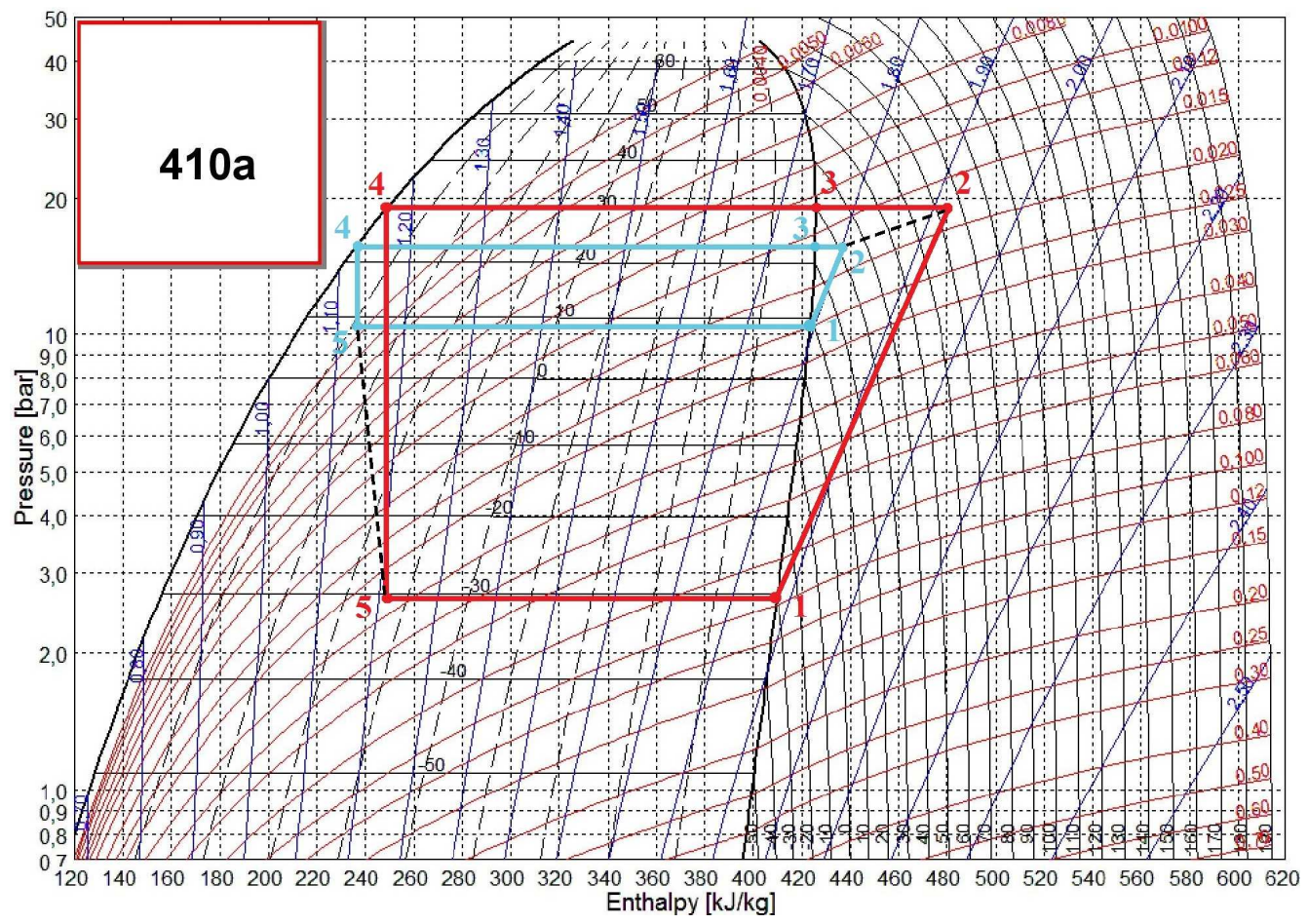

Fig. 4.
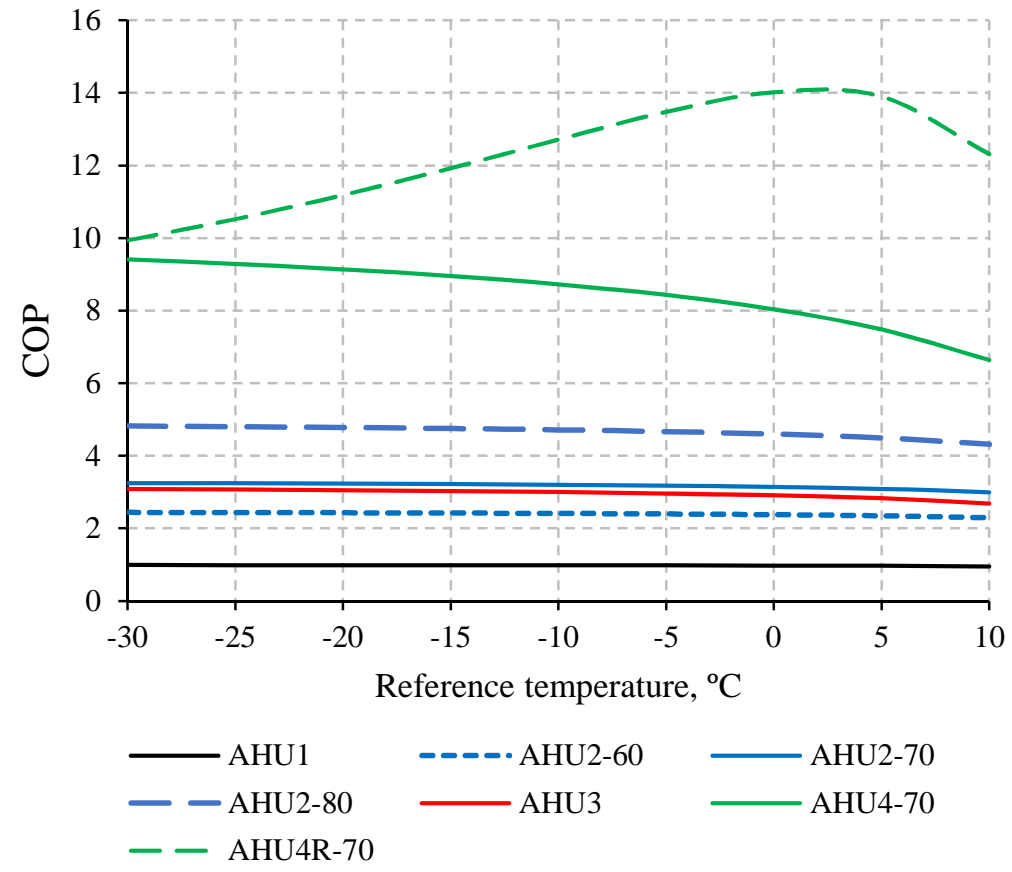

Fig. 5. 


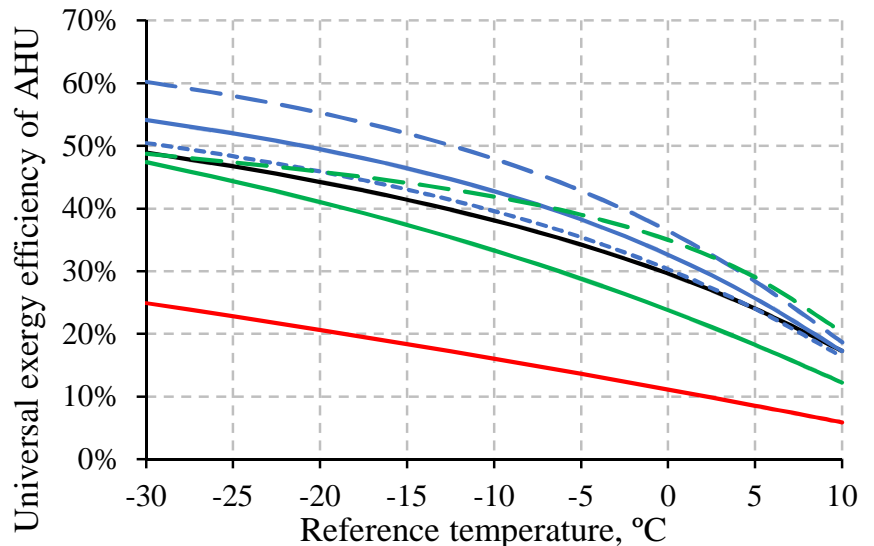

Reference temperature, ${ }^{\circ} \mathrm{C}$

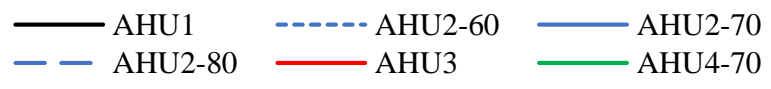

(a)

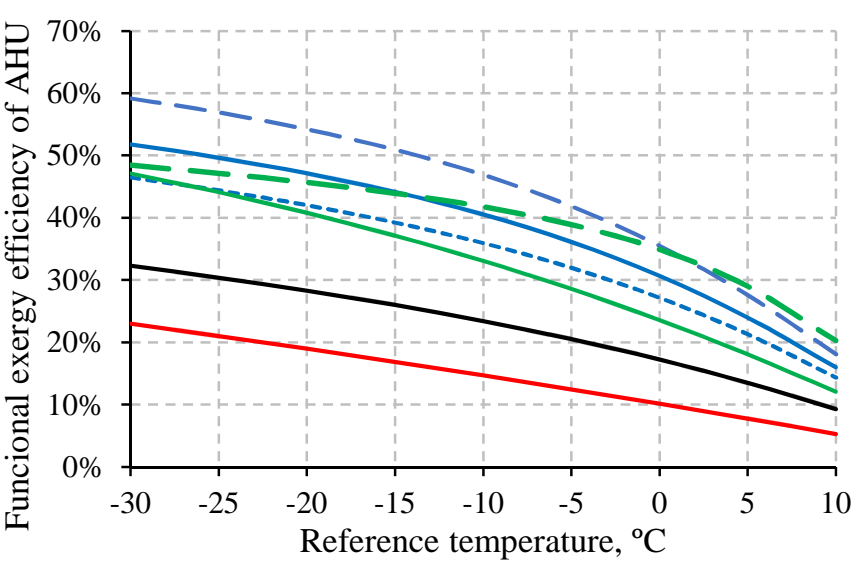

$\begin{array}{lll}- \text { AHU1 } & -\cdots \text { AHU2-60 } & - \text { AHU2-70 } \\ - \text { AHU2-80 } & - \text { AHU3 } & \text { AHU4-70 }\end{array}$

(b)

Fig. 6.

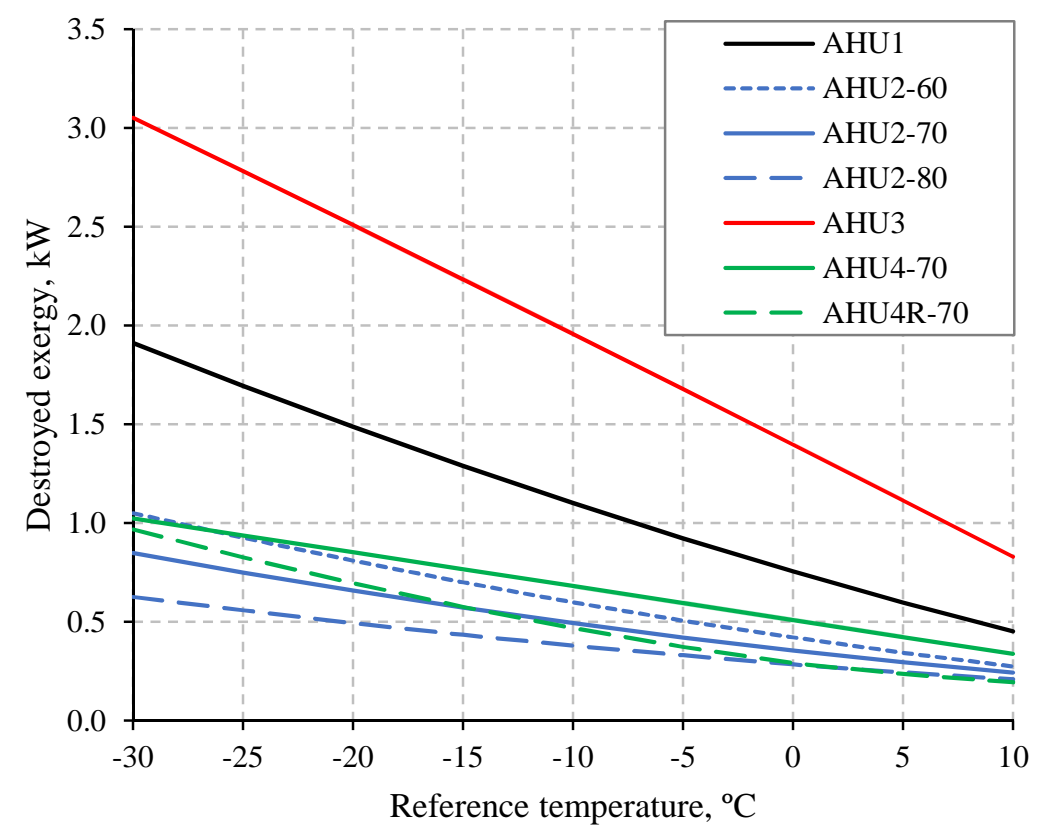

Fig. 7. 


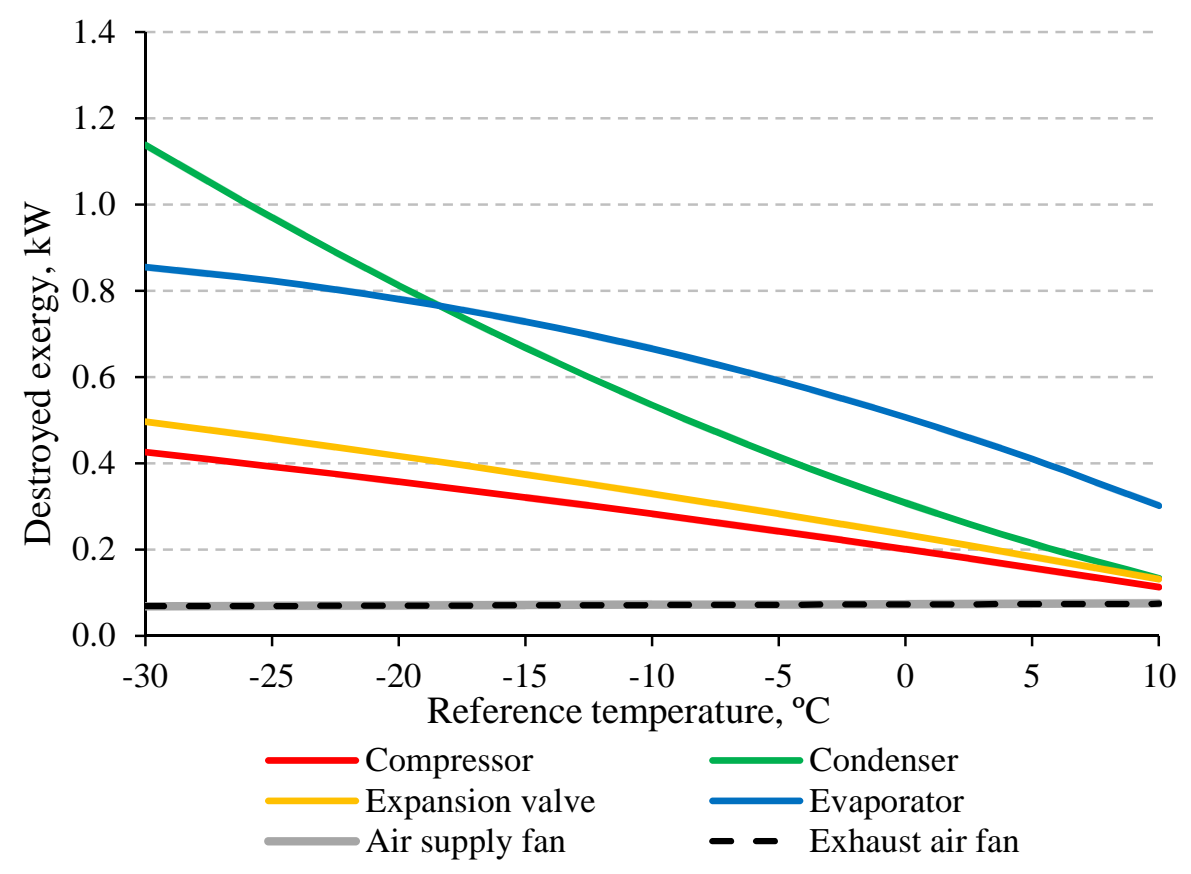

(a)

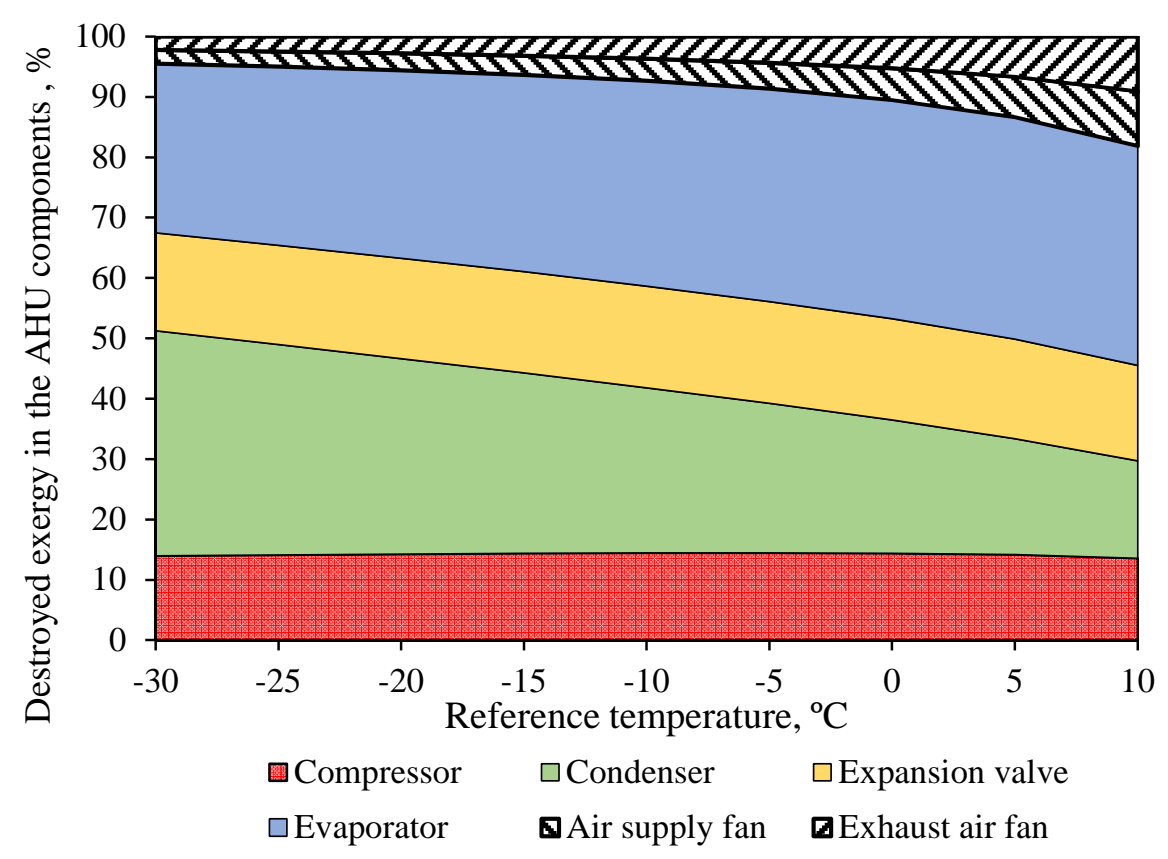

(b)

Fig. 8. 


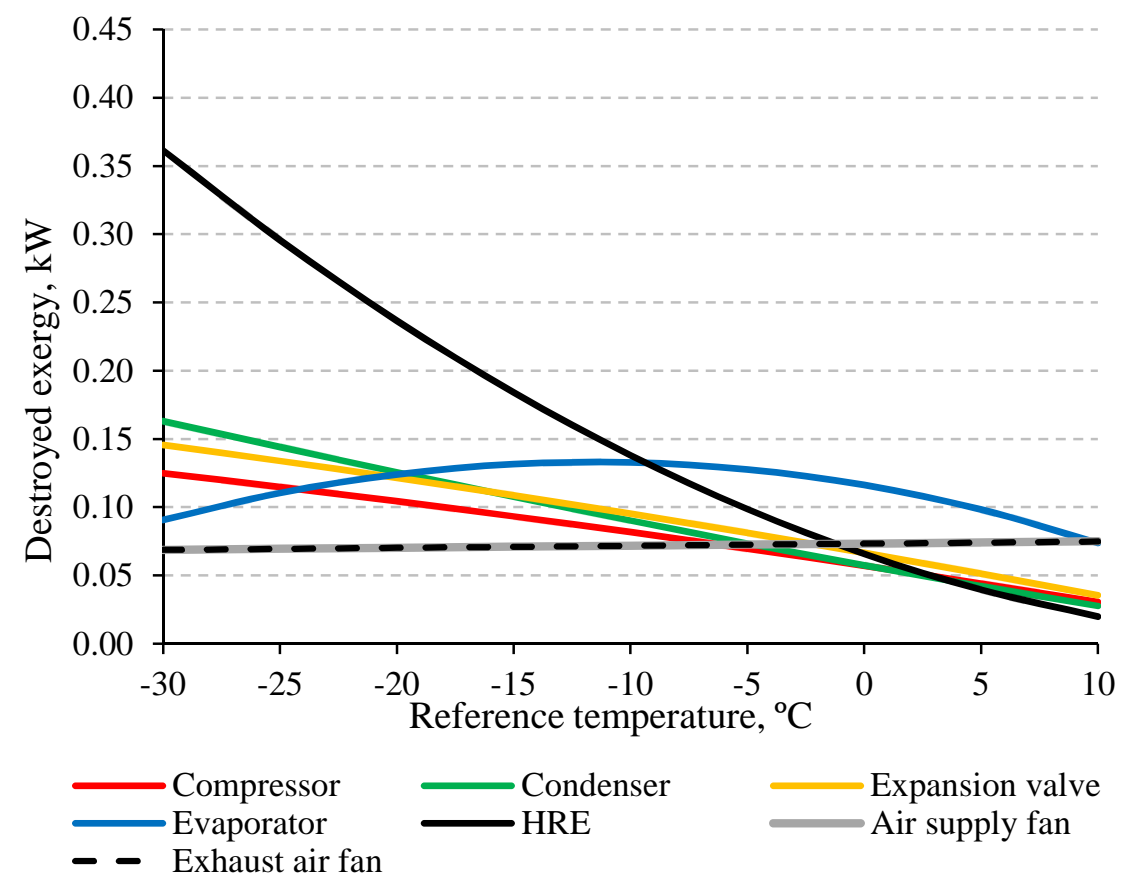

(a)

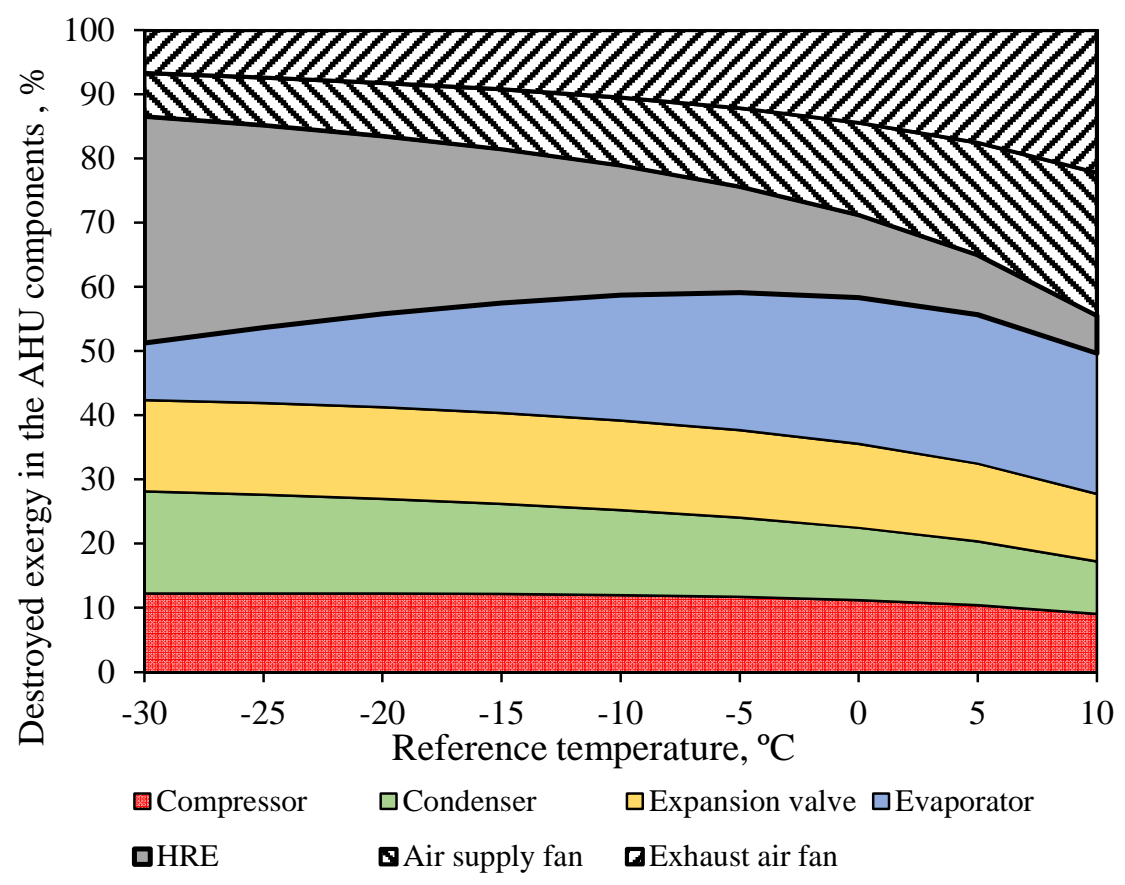

(b)

Fig. 9. 
Table 1. Universal and functional exergy efficiencies (see Figure 2).

\section{Universal exergy efficiency}

$$
\begin{array}{cc}
e_{1}^{+}+e_{3}^{+}=e_{2}^{-}+e_{4}^{-}+l_{\Sigma} & e_{3}^{+}-e_{4}^{-}=e_{2}^{-}-e_{1}^{+}+l_{\Sigma} \\
e_{\text {in }}^{+}=e_{\text {out }}^{-}+l_{\Sigma} & e_{\text {consum }}^{+}=e_{\text {prod }}^{-}+l_{\Sigma} \\
\eta_{U}=\frac{e_{\text {out }}^{-}}{e_{\text {in }}^{+}}=\frac{e_{2}^{-}+e_{4}^{-}}{e_{1}^{+}+e_{3}^{+}} & \eta_{F}=\frac{e_{\text {prod }}^{-}}{e_{\text {consum }}^{+}}=\frac{\left(e_{2}^{-}-e_{1}^{+}\right)}{\left(e_{3}^{+}-e_{4}^{-}\right)}
\end{array}
$$

\section{Functional exergy efficiency}

$$
l_{\Sigma}=e_{\text {in }}^{+}-e_{\text {out }}^{-}=e_{\text {consum }}^{+}-e_{\text {prod }}^{-}=e_{1}^{+}-e_{2}^{-}+e_{3}^{+}-e_{4}^{-}
$$

Table 2. Universal and functional exergy efficiencies for AHU (see Figure 1).

\section{Universal exergy efficiency}

\begin{tabular}{cc}
\hline$e_{\text {in }}^{+}=e^{+}+\left(k_{R}-k_{e}\right)$ & $e_{\text {consum }}^{+}=e^{+}+\left(k_{R}-k_{E}\right)$ \\
\hline$e_{\text {out }}^{-}=\left(k_{R}-k_{e}\right)+\left(k_{E}-k_{e}\right)+e^{-},\left(e^{-}=0\right)$ & $e_{\text {prod }}^{-}=\left(k_{R}-k_{e}\right)+e^{-},\left(e^{-}=0\right)$ \\
\hline$l_{A H U}=e_{\text {in }}^{+}-e_{\text {out }}^{-}=e_{\text {consum }}^{+}-e_{\text {prod }}^{-}=e^{+}-\left(k_{E}-k_{e}\right)$ \\
\hline$\eta_{U_{\text {AHU }}}=1-\frac{l_{A H U}}{e_{\text {in }}^{+}}=1-\frac{e^{+}-\left(k_{E}-k_{e}\right)}{e^{+}+\left(k_{R}-k_{e}\right)}=$ & $\eta_{F_{\text {AHU }}}=1-\frac{l_{A H U}}{e_{\text {consum }}^{+}}=1-\frac{e^{+}-\left(k_{E}-k_{e}\right)}{e^{+}+\left(k_{R}-k_{E}\right)}=$ \\
$=\frac{\left(k_{R}-k_{e}\right)+\left(k_{E}-k_{e}\right)}{e^{+}+\left(k_{R}-k_{e}\right)}$ & $=\frac{\left(k_{R}-k_{e}\right)}{e^{+}+\left(k_{R}-k_{E}\right)}$ \\
\hline
\end{tabular}


Table 3. Data used in calculations.

\begin{tabular}{ll}
\hline Parameter & Value \\
\hline Air flow rate & $560 \mathrm{~m}^{3} / \mathrm{h}$ \\
\hline Power input for fans (supply and exhaust), & $2 \times 77 \mathrm{~W}$ \\
\hline Room air temperature & $22^{\circ} \mathrm{C}$ \\
\hline Environment (reference) temperature range & $T_{e}=-30 \ldots 10^{\circ} \mathrm{C}$ \\
\hline Effectiveness of HRE, $\varepsilon_{T}$, for AHU 2 and 4 & 60,70 or $80 \%$ \\
\hline Isentropic efficiency of the compressor of the HP & 0.80 \\
\hline Power consumption efficiency of the fan & 0.82 \\
\hline
\end{tabular}

